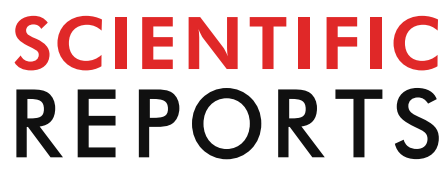

natureresearch

Check for updates

\title{
Diagnostic value
}

of the $y$-glutamyltransferase and alanine transaminase ratio, alpha-fetoprotein, and protein induced by vitamin $\mathrm{K}$ absence or antagonist II in hepatitis B virus-related hepatocellular carcinoma

\author{
Guangrong Wang ${ }^{1,2,3,4}$, Xiaolan $\mathrm{Lu}^{1,2,4}$, Qin Du ${ }^{1,2}$, Guoyuan Zhang ${ }^{1,2}$, Dongsheng Wang ${ }^{1,3}$, \\ Qiang Wang ${ }^{1,2,3 凶}$ \& Xiaolan Guo ${ }^{1,2,3 凶}$
}

Hepatocellular carcinoma is a common type of malignancy with a poor prognosis. Identification and utilisation of markers for monitoring and diagnosis are urgently needed. Alpha-fetoprotein (AFP) and Protein Induced by Vitamin K Absence or Antagonist-II (PIVKA-II) have been proved to be efficient biomarkers for hepatitis B virus (HBV)-related hepatocellular carcinoma (HCC). The combination of the two markers could improve the detection rate. However, these indicators cannot meet the need of clinical diagnosis.It is necessary to discover novel serological markers and more cost-effective, appropriate combination of these markers for the diagnosis and surveillance of HBV-related HCC. Accordingly, in this study, we aimed to evaluate the diagnostic value of $\gamma$-glutamyltransferase ( $\gamma$-GT) to alanine amino transferase (ALT) ratio alone or in combination with AFP and PIVKA-II for HBVrelated HCC. 234 patients with HBV-related HCC and 396 patients with chronic hepatitis B (CHB) were enrolled in this study and approved by the institutional review board. Our results showed levels of AFP and PIVKA-II, and Y-GT/ALT ratio in cases with early-stage HCC, HCC, HCC plus HBV DNA positivity, and HCC plus HBV DNA negativity were higher than those in the corresponding $\mathrm{CHB}$ control group. Additionally, the levels of serum AFP and PIVKA-II, and the $\mathrm{y}$-GT/ALT ratio were positively correlated with tumour sizes in patients with HBV-related HCC. The areas under the ROC curves (AUROCs) of the $\gamma$-GT/ALT ratio in patients with early-stage HCC, HCC, HCC plus HBV DNA positivity, and HCC plus HBV DNA negativity were $0.795,0.846,0.855$, and 0.837 , respectively; AUROCs of combination of the $\gamma$-GT/ALT ratio and PIVKA-II were $0.858,0.928,0.948$, and 0.902 , respectively; AUROCs of combination of the $\gamma$-GT/ALT ratio and AFP were $0.822,0.886,0.896$, and 0.873 , respectively;AUROCs of combination of the $\gamma$-GT/ALT ratio and PIVKA-II with AFP were $0.857,0.928,0.946$, and 0.907 , respectively, and AUROCs of combination of PIVKA-II and AFP were $0.804,0.904,0.942$, and 0.863 , respectively. In conclusion, the $\mathrm{Y}$-GT/ALT ratio was a useful biomarker for the diagnosis of HBV-related

${ }^{1}$ Department of Laboratory Medicine, Affiliated Hospital of North Sichuan Medical College, Nanchong, Sichuan, People's Republic of China. ${ }^{2}$ Faculty of Laboratory Medicine, Center for Translational Medicine, North Sichuan Medical College, Nanchong, Sichuan, People's Republic of China. ${ }^{3}$ Department of Laboratory Medicine, North Sichuan Medical College, Nanchong, Sichuan, People's Republic of China. ${ }^{4}$ These authors contributed equally: Guangrong Wang and Xiaolan Lu. ${ }^{凶}$ email: wqiang_1981@126.com; alan5200@hotmail.com 


\section{HCC and that the combination of AFP and PIVKA-II with the $y$-GT/ALT ratio could improve the diagnostic value of these biomarkers for HBV-related HCC. Moreover, the ratio of $Y$-GT/ALT may be a useful index in monitoring patients for progression of HBV-related HCC.}

Hepatocellular carcinoma (HCC) is the sixth most common type of malignant tumour and the third leading cause of cancer-related death ${ }^{1}$. The occurrence of HCC can be caused by many factors, including hepatitis B virus (HBV)/hepatitis $\mathrm{C}$ virus (HCV) infection and alcohol consumption ${ }^{2}$. Among these factors, $\mathrm{HBV}$ infection is most closely related to the occurrence of HCC, accounting for $75-80 \%$ of virus-related HCC $^{3}$. Attribute to HBV infection, the incidence of HCC is higher in China than the average incidence worldwide ${ }^{4-8}$, about 330,000 people die of HCC every year ${ }^{9-11}$. Therefore, there is no doubt that the health and economic burden of HBVrelated HCC is particularly challenging and serious in China. Morever, about 50\% HCC cases diagnosed are at advanced stage when curative treatments are very limited, and 5-year survival rate is considerably low ${ }^{12}$. Thus, screening, early detecting, and diagnosing of HCC among patients with CHB is urgently needed.

Currently, Alpha-fetoprotein (AFP) and protein induced by vitamin K absence or antagonist II (PIVKA-II) are widely used biomarkers in HCC diagnosis ${ }^{13-16}$. These markers have been written into the guidelines for HCC diagnosis published by the National Society of Hepatology of different countries ${ }^{17-19}$. However, owing to increased AFP levels in patients with hepatitis and cirrhosis, not all patients with HCC show high levels of AFP, and approximately $40 \%$ of patients with $\mathrm{HCC}$ have negative $\mathrm{AFP}^{20}$. However, the sensitivity and specificity of AFP in the diagnosis of HCC are not satisfactory, making AFP unsuitable for clinical applications ${ }^{21}$. PIVKA-II, also known as demethoxy prothrombin, is a type of prothrombin that does not use vitamin $\mathrm{K}$ for hepatocyte synthesis, resulting in deficiencies in synthesis and absence of coagulation function. When HCC occurs, the absence of vitamin K-dependent carboxylase in malignant hepatocytes leads to insufficient carboxylation of prothrombin precursor, leading to accumulation of PIVKA-II ${ }^{22}$. As a tumour marker for the diagnosis of HCC, PIVKA-II has a higher diagnostic value than $\mathrm{AFP}^{14,23}$, particularly for AFP-negative HCC or early-stage HCC ${ }^{24-26}$. Some studies have shown that PIVKA-II has a sensitivity of more than $90 \%$ for HCC diagnosis, although its sensitivity for early-stage HBV-related HCC detection is less than $70 \%{ }^{23,27-29}$.

$\gamma$-Glutamyl transpeptidase $(\gamma-\mathrm{GT})$ is a membrane-binding enzyme that is essential for glutathione synthesis and is considered a biomarker of liver cell damage $\mathrm{e}^{30} \cdot \gamma$-GT in serum is mainly derived from the liver, and the level of $\gamma$-GT is abnormally elevated in various hepatobiliary diseases. Many studies have shown that intrahepatic obstruction leads to cholestasis, which induces the liver to produce large amounts of $\gamma$-GT in patients with HCC, and tumour cells can produce $\gamma$-GT themselves; thus, the level of $\gamma$-GT in serum is abnormally elevated in patients with HCC. However, in other liver diseases, such as viral hepatitis, alcoholic hepatitis, and cirrhosis, the level of $\gamma$-GT in serum is also abnormally elevated ${ }^{31-34}$. Therefore, the specificity of $\gamma$-GT in the diagnosis of HCC is only approximately $30 \%{ }^{35}$. Based on these analyses, $\gamma$-GT cannot be used as an effective index to diagnose HCC, but could be used as an effective indicator for evaluation of patient liver function. Alanine aminotransferase (ALT) is an enzyme that participates in the metabolism of human proteins. ALT is widely expressed in various tissues and organs in humans, with the highest expression observed in the mitochondria of hepatocytes. When $1 \%$ of hepatocytes are destroyed, ALT is released into the blood, thereby increasing the activity of ALT in the blood. Therefore, this protein is often used as a biomarker to evaluate damage to hepatocytes. In acute and chronic viral hepatitis, alcoholic hepatitis, and cirrhosis, the level of ALT is elevated to varying degrees, whereas in patients with HCC, ALT is not elevated or is even decreased ${ }^{13,36}$.

Accordingly, in this study, we evaluated whether the ratio of $\gamma$-GT to ALT ( $\gamma$-GT/ALT ratio) could be used to differentiate HBV-related HCC from CHB by increasing the gap between HCC and CHB. We also examined whether this ratio could be applied to the diagnosis and evaluation of HBV-related HCC and explored whether the combination of the $\gamma$-GT/ALT ratio and PIVKA-II and AFP, as known biomarkers for the diagnosis of HCC, could improve the diagnostic value of PIVKA-II and AFP for HBV-related HCC.

\section{Materials and methods}

Study setting and patients. In total, 630 patients with $\mathrm{CHB}$, including 234 patients with HBV-related HCC and 396 patients with CHB with other liver diseases, were retrospectively enrolled at the Affiliated Hospital of Northern Sichuan Medical College from January 2017 to November 2018. HBV-related HCC patients were divided into the following categories: Early-stage HCC patients, HCC patients, HCC patients plus HBV DNA positivity (HBV DNA+), and HCC patients plus HBV DNA negative (HBV DNA-). Among the 234 patients with HCC, 94 had early-stage HCC, 110 had HCC with HBV DNA+, and 124 had HCC with HBV DNA-. The diagnosis of HCC was made in accordance with the standards of the guidelines for the diagnosis and treatment of primary HCC issued by the Chinese Society of Clinical Oncology (2018.V1). Early-stage HCC was defined as the presence of only a single tumour in the liver that was less than or equal to $5.0 \mathrm{~cm}$, with no vascular invasion and extrahepatic metastasis ${ }^{14}$. Of the 396 patients with $\mathrm{CHB}, 190$ patients had cirrhosis, 285 patients were HBV DNA+, and 111 patients were HBV DNA-. Diagnoses of CHB infection and cirrhosis were carried out in accordance with the revised guidelines for the prevention and treatment of $\mathrm{CHB}$ infection from the Chinese Society of Hepatology 37 .

Measurement of $\boldsymbol{\gamma}$-GT, ALT, AFP, PIVKA-II, and HBV DNA. Serum levels of $\gamma$-GT and ALT were determined using a biochemical rate-assay (AU5800; Beckman Coulter, Inc., USA). Serum levels of AFP were measured using an electrochemiluminescence immunoassay (Cobas E602; Roche, Inc., Germany). Serum levels of PIVKA-II were determined using a chemiluminescent microparticle immunoassay (Architect i1000; Abbott Laboratories, USA). Serum levels of HBV DNA were determined by real-time polymerase chain reaction (Light- 


\begin{tabular}{|l|l|l|l|}
\hline & CHB $(\mathbf{n}=\mathbf{3 9 6})$ & HCC $(\mathbf{n}=\mathbf{2 3 4})$ & $\boldsymbol{P}$ value \\
\hline Age (years) & $48(39-59)$ & $54(47-63)$ & $<0.001$ \\
\hline Sex (male:female) & $311: 85$ & $201: 33$ & 0.031 \\
\hline PIVKA-II $(\mathrm{mAU} / \mathrm{mL})$ & $22.32(15.96-36.84)$ & $4,191.74(294.12-24,580.91)$ & $<0.001$ \\
\hline AFP $(\mathrm{ng} / \mathrm{mL})$ & $30.45(5.32-117.43)$ & $576.30(22.53-10,543.48)$ & $<0.001$ \\
\hline$\gamma$-GT(U/L) & $92.60(46.03-162.85)$ & $153.70(74.18-313.30)$ & $<0.001$ \\
\hline ALT(U/L) & $154.60(44.25-538.25)$ & $47.00(29.75-84.00)$ & $<0.001$ \\
\hline$\gamma$-GT/ALT & $0.57(0.23-1.25)$ & $3.22(1.44-5.93)$ & $<0.001$ \\
\hline HBV DNA+, $\mathrm{n}(\%)$ & $285(71.97 \%)$ & $110(47.01 \%)$ & NA \\
\hline Early-stage HCC, $n(\%)$ & NA & $94(40.17 \%)$ & NA \\
\hline
\end{tabular}

Table 1. Characteristics of the study population $(n=630)$. Data are expressed as medians (interquartile ranges) or numbers (\%). CHB chronic hepatitis B, HCC hepatocellular carcinoma, PIVKA-II protein induced by vitamin $\mathrm{K}$ absence or antagonist II, AFP alpha-fetoprotein, $\gamma$-GT $\gamma$-glutamyltransferase, $A L T$ alanine transaminase, NA not applicable.

Cycler 480II; Roche, Inc.). The results were interpreted as follows: $\mathrm{HBV}$ DNA $\geq 500 \mathrm{IU} / \mathrm{mL}$, positive (HBV DNA+); and HBV DNA < $500 \mathrm{IU} / \mathrm{mL}$, negative (HBV DNA-) ${ }^{16}$.

Data processing for the combined evaluation of $\gamma$-GT/ALT, PIVKA-II, and AFP. The receiver operating characteristic (ROC) curves were used to determine the diagnostic cut-off values of the $\gamma$-GT/ALT ratio, AFP, and PIVKA-II for HBV-related HCC. The fold changes in the serum levels of the $\gamma$-GT/ALT ratio, AFP, and PIVKA-II relative to the corresponding diagnostic cut-off values were expressed using the $\mathrm{M}_{\text {cut-off }}$. We evaluated the diagnostic values of the combined detection of biomarkers in HBV-related HCC by analysing the sums of the $\mathrm{M}_{\text {cut-off }}$ of the corresponding biomarkers.

Statistical analysis. Data are expressed as the median (interquartile range) or number (\%). Two groups were compared using Mann-Whitney U tests. Pearson's chi-square tests were used for comparisons of sex. Pearson correlation analysis was used for two-factor correlation analysis. ROC curves were used to determine the diagnostic cut-off values, area under the ROCs (AUROCs), diagnostic sensitivities, and specificities. Statistical analyses were performed using SPSS, version 19.0 (SPSS Inc., USA) and Medcalc, version 12.3 (MedCalc Software bvba, Ostend, Belgium). Results with $P$ values of less than 0.05 by two-tailed t tests were considered significant.

Ethical approval and informed consent. The study protocol was approved by the Ethics Committee of the Affiliated Hospital of North Sichuan Medical College, Nanchong, China. All study participants provided informed consent and all methods were performed in accordance with the relevant guidelines and regulations of the committee.

\section{Results}

Comparison of clinical characteristics between the HCC and CHB control groups. The clinical characteristics of 234 patients with HCC and 396 patients with CHB (the control group) are shown in Table 1. The data showed that patients in both groups were predominately male and that the median age of patients with HCC was 54 (47-63) years, which was higher than that in the CHB control group (median 48 years [range 39-59 years]; $P<0.001$ ). The serum levels of PIVKA-II, AFP, and $\gamma$-GT, and serum $\gamma$-GT/ALT ratio in patients with HCC were higher than those in CHB control patients $(P<0.001)$. In contrast, serum levels of ALT were lower in patients with HCC than in CHB controls $(P<0.001)$.

Serum PIVKA-II and AFP levels and the serum $\mathrm{Y}$-GT/ALT ratio in patients with CHB, early-stage HCC, and advanced HCC. Serum PIVKA-II and AFP levels and the serum $\gamma$-GT/ALT ratio were positively correlated with tumour size in patients with HCC $(\mathrm{r}=0.520, P<0.001 ; \mathrm{r}=0.328, P<0.001 ; \mathrm{r}=0.209, P=0.001$, respectively; Fig. 1A-C). The serum levels of PIVKA-II and AFP and the serum $\gamma$-GT/ALT ratio in patients with early-stage HCC were significantly lower than those in patients with advanced HCC $(P<0.001)$. Both groups displayed significantly higher serum levels of PIVKA-II and AFP and higher serum $\gamma$-GT/ALT ratios compared with those in controls with CHB $(P<0.001$; Fig. 1D-F, Table 2).

Diagnostic value of $\gamma$-GT/ALT ratio, AFP and PIVKA-II in early-stage HCC patients. When the cut-off values of the $\gamma$-GT/ALT ratio, AFP and PIVKA-II levels were set as $1.245,556.90 \mathrm{ng} / \mathrm{mL}$, and $87.63 \mathrm{mAu} /$ $\mathrm{mL}$, respectively, for the diagnosis of early-stage HCC, the AUROC of the $\gamma$-GT/ALT ratio was 0.795 , which was higher than that of AFP $(0.617 ; P<0.001$; Fig. 2A).

When combined with AFP in early-stage HCC, the AUROC of PIVKA-II decreased (0.804 versus 0.851 , respectively). However, the difference was not significant between combined diagnosis and single diagnosis $(P=0.228)$. When combined with the $\gamma$-GT/ALT ratio for the diagnosis of early-stage HCC, the AUROC of 

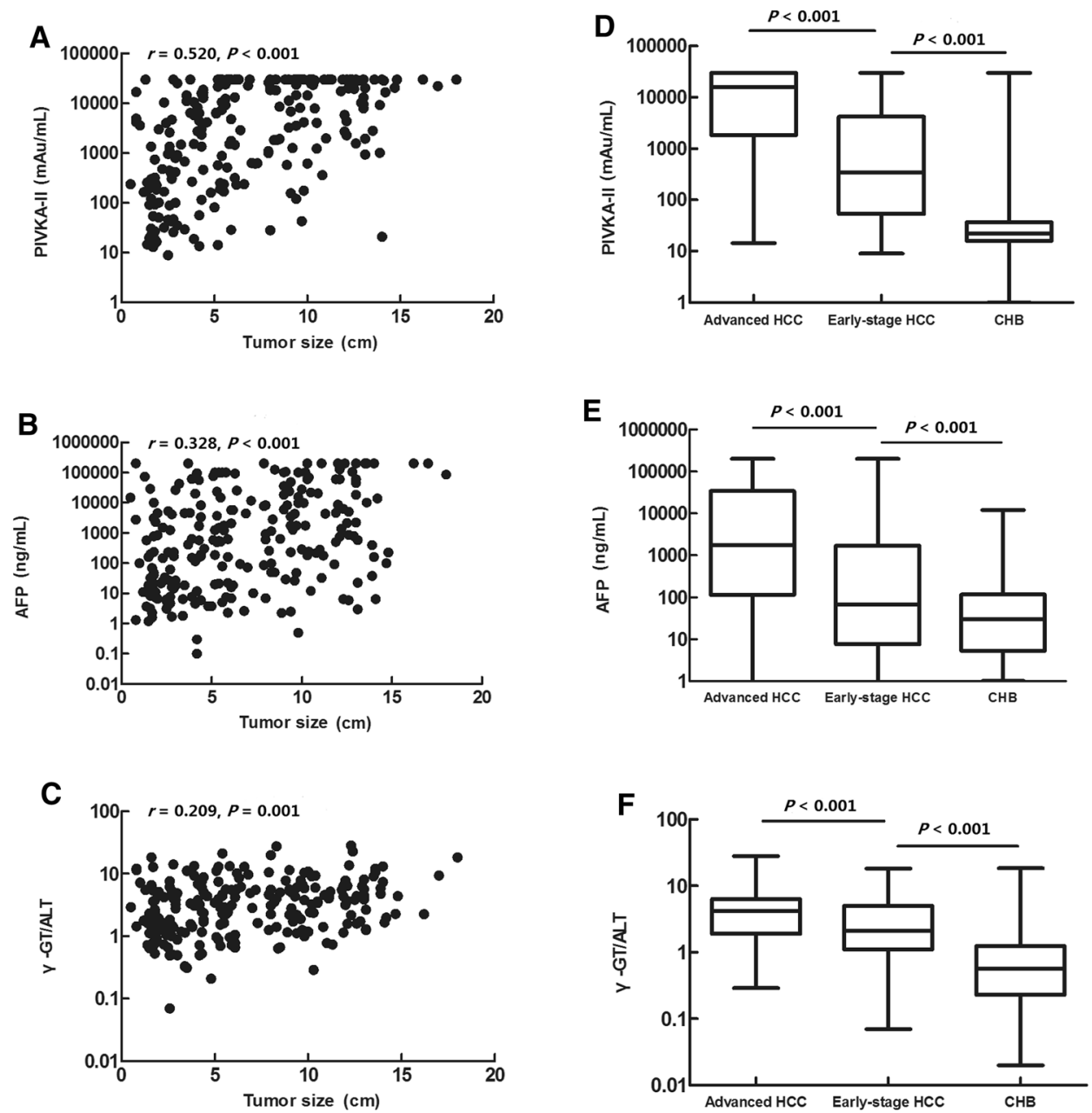

Figure 1. (A-C) Correlations of PIVKA-II, AFP, and the $\gamma$-GT/ALT ratio with tumour size. (D-F) Comparison of serum levels of PIVKA-II and AFP and the serum $\gamma$-GT/ALT ratio in patients with advanced HCC, earlystage $\mathrm{HCC}$, and $\mathrm{CHB}$.

\begin{tabular}{|l|l|c|c|l|}
\hline & CHB $(\mathbf{n}=396)$ & Early-stage HCC $(\mathbf{n}=\mathbf{9 4})$ & Advanced HCC $(\mathbf{n}=\mathbf{1 4 0})$ & $\boldsymbol{P}$ value \\
\hline PIVKA-II $(\mathrm{mAU} / \mathrm{mL})$ & $22.32(15.96-36.84)$ & $342.19(53.56-4,208.13)^{\mathrm{a}}$ & $15,701.03(1,843.90-30,000.00)^{\mathrm{ab}}$ & 0.000 \\
\hline AFP $(\mathrm{ng} / \mathrm{mL})$ & $30.45(5.32-117.43)$ & $66.20(7.63-1,718.80)^{\mathrm{a}}$ & $1,767.60(115.83-33,996.28)^{\mathrm{ab}}$ & 0.000 \\
\hline$\gamma$-GT/ALT & $0.57(0.23-1.25)$ & $2.13(1.11-5.03)^{\mathrm{a}}$ & $4.15(1.91-6.36)^{\mathrm{ab}}$ & 0.000 \\
\hline
\end{tabular}

Table 2. Serum levels of PIVKA-II and AFP and the serum $\gamma$-GT/ALT ratio in patients with CHB, early-stage $\mathrm{HCC}$, and advanced HCC. Data are expressed as medians (interquartile ranges). $C H B$ chronic hepatitis $\mathrm{B}$, HCC hepatocellular carcinoma, PIVKA-II protein induced by vitamin $\mathrm{K}$ absence or antagonist II, AFP alphafetoprotein, $\gamma$-GT/ALT the ratio of $\gamma$-glutamyltransferase to alanine aminotransferase. ${ }^{\text {a } V e r s u s ~} \mathrm{CHB} .{ }^{\mathrm{b}}$ Versus early-stage HCC.

PIVKA-II increased ( 0.858 versus 0.851 , respectively), and when combined with the $\gamma$-GT/ALT ratio for earlystage HCC diagnosis, the AUROC of AFP increased (0.822 versus 0.617 , respectively; $P<0.001)$. When PIVKA-II was combined with the $\gamma$-GT/ALT ratio and AFP for diagnosis of early-stage HCC, there was almost no difference between AUROCS for combined and single diagnosis ( 0.857 versus 0.851 , respectively; $P=0.858$; Fig. $2 \mathrm{~A}, \mathrm{~B}$ ).

Diagnostic value of PIVKA-II, AFP, and the $\gamma$-GT/ALT ratio in patients with HCC. When the cut-off values of the $\gamma$-GT/ALT ratio, AFP and PIVKA-II levels were set as $1.395,499.80 \mathrm{ng} / \mathrm{mL}$, and $87.63 \mathrm{mAu} / \mathrm{mL}$, respectively, the AUROC of PIVKA-II for diagnosing HCC was significantly higher than that of AFP and $\gamma$-GT/ALT $(P<0.001, P<0.001$, respectively), whereas the AUROC of the $\gamma$-GT/ALT ratio for diagnosing HCC was significantly higher than that of AFP $(P<0.001$; Fig. 2 C). Compared with the results in patients with early-stage 

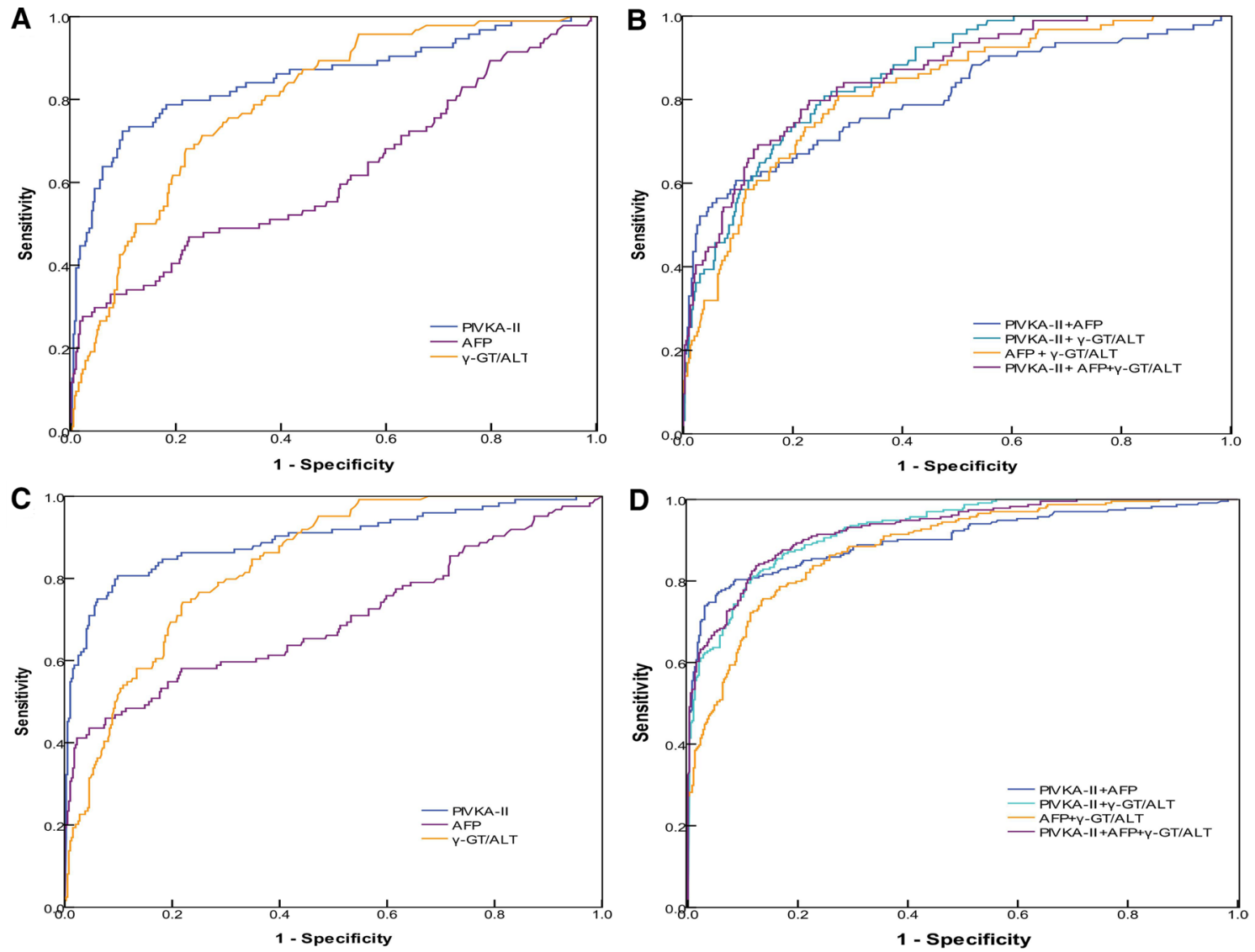

Figure 2. (A, B) ROC curves of PIVKA-II, AFP, the $\gamma$-GT/ALT ratio, and combinations of various biomarkers in patients with early-stage HCC; patients with CHB served as controls. (C, D) ROC curves of PIVKA-II, AFP, the $\gamma$-GT/ALT ratio, and combinations of various biomarkers in patients with HCC; patients with CHB served as controls.

HCC, the diagnostic value of AFP and PIVKA-II increased in patients with advanced HCC $(P=0.002, P=0.010)$; however, there were no significant differences in the diagnostic value of the $\gamma$-GT/ALT ratio between early-stage HCC and advanced HCC $(P=0.072)$.

When combined with AFP in HCC, the AUROC of PIVKA-II decreased (0.904 versus 0.925 , respectively), and there were no significant differences in AUROCs between combined diagnosis and single diagnosis $(P=0.255)$. When combined with the $\gamma$-GT/ALT ratio for the diagnosis of HCC, the AUROC of PIVKA-II increased (0.928 versus 0.925 , respectively). When combined with the $\gamma$-GT/ALT ratio for HCC diagnosis, the AUROC of the $\gamma$-GT/ALT ratio and AFP increased ( 0.886 versus 0.846 and 0.886 versus 0.745 , respectively; $P=0.044, P<0.001$, respectively). When PIVKA-II was combined with the $\gamma$-GT/ALT ratio and AFP for diagnosis of HCC, there were no significant differences between combined and single diagnosis $(0.928$ versus 0.925 , respectively; $P=0.848$; Fig. 2C,D). The diagnostic performance values of PIVKA-II, AFP, and the $\gamma$-GT/ALT ratio for early-stage HCC and HCC are shown in Table 3.

Serum levels of PIVKA-II and AFP and the serum $\gamma$-GT/ALT ratio in patients with HCC according to HBV DNA status. Serum levels of AFP and PIVKA-II in patients with HCC were higher in those positive for HBV DNA than in those negative for HBV DNA ( $P=0.031$ and $P=0.003$, respectively). There were no significant differences in $\gamma$-GT/ALT ratios between the two groups $(P=0.330$; Fig. $3 \mathrm{~A}-\mathrm{C}$, Table 4$)$. Serum levels of AFP in patients with $\mathrm{CHB}$ positive for HBV DNA were significantly higher than those in patients with CHB negative for HBV DNA $(P<0.001$; Fig. $3 \mathrm{E})$. In contrast, the $\gamma$-GT/ALT ratio in patients with CHB was significantly lower in patients positive for HBV DNA than in patients negative for HBV DNA $(P<0.001$; Fig. 3F $)$; there were no significant differences in PIVKA-II levels between the two groups $(P=0.329$; Fig. 3D). Serum levels of PIVKA-II and AFP and the serum $\gamma$-GT/ALT ratio were not correlated with serum levels of HBV DNA in patients with HCC who were positive for $\operatorname{HBV}$ DNA $(P=0.503, P=0.248$, and $P=0.336$, respectively; Fig. 3G-I).

Diagnostic value of PIVKA-II, AFP, and the $\mathrm{Y}$-GT/ALT ratio in patients with $\mathrm{HCC}$ who were positive for HBV DNA. Serum levels of PIVKA-II and AFP and the serum $\gamma$-GT/ALT ratio in patients with HCC who were positive for HBV DNA were higher than those in patients with $\mathrm{CHB}$ who were positive for HBV DNA $(P<0.001, P<0.001, P<0.001$, respectively; Fig. 4 A-C). 


\begin{tabular}{|c|c|c|c|c|c|c|c|c|c|c|c|c|}
\hline & \multicolumn{6}{|c|}{ Early-stage HCC } & \multicolumn{6}{|l|}{ HCC } \\
\hline & \begin{tabular}{|l|} 
Cut-off \\
\end{tabular} & AUROC $(95 \%$ CI $)$ & SEN (\%) & SPE (\%) & PPV (\%) & NPV (\%) & Cut-off & AUROC (95\% CI) & SEN (\%) & SPE (\%) & PPV (\%) & NPV (\%) \\
\hline $\begin{array}{l}\text { PIVKA-II (mAu/ } \\
\mathrm{mL})\end{array}$ & 87.63 & \begin{tabular}{|l|}
$0.851(0.801-$ \\
$0.901)$
\end{tabular} & 72.30 & 90.20 & 63.55 & 93.21 & 87.63 & $\begin{array}{l}0.925(0.901- \\
0.950)\end{array}$ & 86.80 & 90.20 & 83.88 & 92.01 \\
\hline $\operatorname{AFP}(\mathrm{ng} / \mathrm{mL})$ & 556.90 & $\begin{array}{l}0.617(0.547- \\
0.687)\end{array}$ & 33.00 & 92.40 & 50.82 & 85.31 & 499.80 & $\begin{array}{l}0.745(0.702- \\
0.787)\end{array}$ & 52.10 & 91.40 & 78.21 & 76.37 \\
\hline$\gamma$-GT/ALT & 1.245 & \begin{tabular}{|l|}
$0.795(0.748-$ \\
$0.841)$
\end{tabular} & 71.30 & 75.00 & 40.36 & 91.67 & 1.395 & $\begin{array}{l}0.846(0.816- \\
0.876)\end{array}$ & 77.40 & 78.00 & 67.54 & 85.36 \\
\hline PIVKA-II \& AFP & NA & \begin{tabular}{|l|}
$0.804(0.748-$ \\
$0.860)$
\end{tabular} & 60.60 & 90.40 & 60.00 & 90.63 & NA & $\begin{array}{l}0.904(0.876- \\
0.931)\end{array}$ & 80.30 & 91.40 & 84.68 & 88.73 \\
\hline $\begin{array}{l}\text { PIVKA-II\& } \gamma \text {-GT/ } \\
\text { ALT }\end{array}$ & NA & \begin{tabular}{|l|}
$0.858(0.820-$ \\
$0.895)$
\end{tabular} & 80.90 & 74.20 & 42.70 & 94.23 & NA & $\begin{array}{l}0.928(0.908- \\
0.947)\end{array}$ & 85.50 & 83.80 & 75.76 & 90.71 \\
\hline AFP \& $\gamma$-GT/ALT & NA & \begin{tabular}{|l|}
$0.822(0.775-$ \\
$0.868)$
\end{tabular} & 80.90 & 71.70 & 40.43 & 94.04 & NA & $\begin{array}{l}0.886(0.859- \\
0.912)\end{array}$ & 78.60 & 83.30 & 73.60 & 86.84 \\
\hline $\begin{array}{l}\text { PIVKA-II \& AFP \& } \\
\gamma \text {-GT/ALT }\end{array}$ & NA & \begin{tabular}{|l|}
$0.857(0.816-$ \\
$0.898)$
\end{tabular} & 79.80 & 77.00 & 45.18 & 94.14 & NA & $\begin{array}{l}0.928(0.908- \\
0.949)\end{array}$ & 83.80 & 87.60 & 80.00 & 90.13 \\
\hline
\end{tabular}

Table 3. Performance value of PIVKA-II, AFP, and the $\gamma$-GT/ALT ratio in patients with early-stage HCC and HCC. HCC hepatocellular carcinoma, SEN sensitivity, SPE specificity, $P P V$ positive predictive value, NPV negative predictive value, $P I V K A-I I$ protein induced by vitamin $\mathrm{K}$ absence or antagonist II, AFP alphafetoprotein, $\gamma$-GT/ALT ratio of $\gamma$-glutamyltransferase to alanine transaminase, $N A$ not applicable.

A

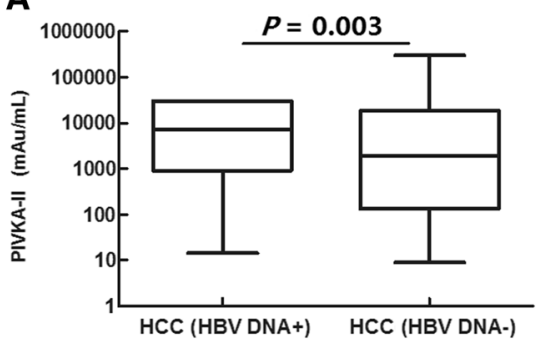

B

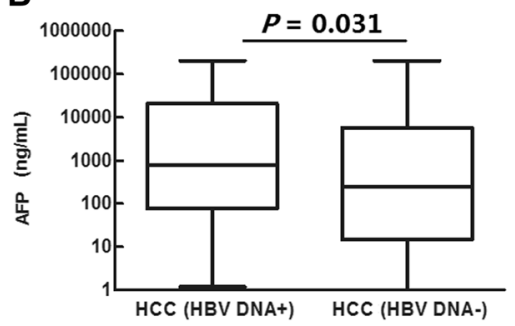

C

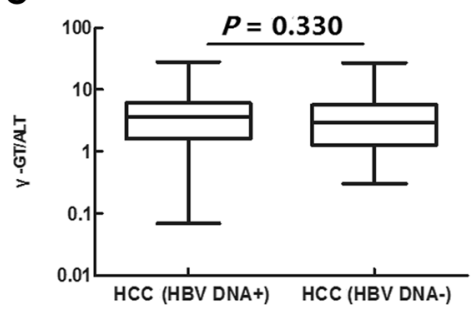

D

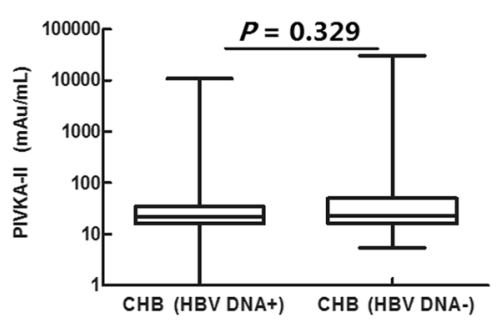

E

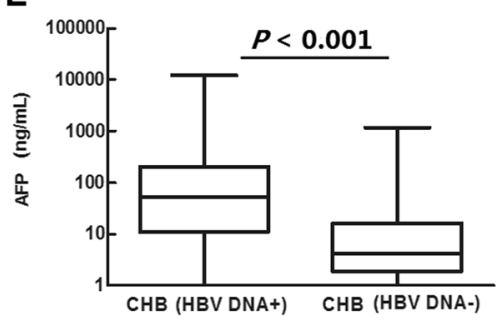

$\mathbf{F}$

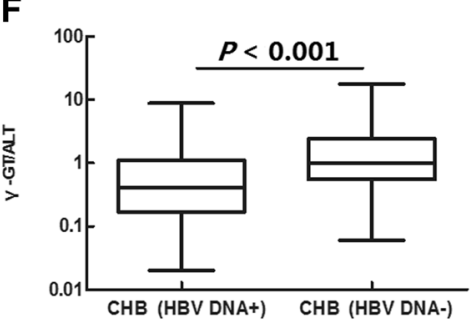

G

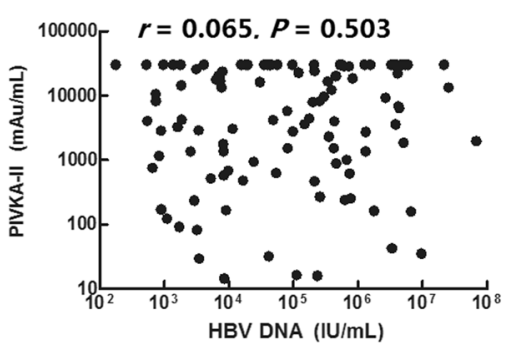

H

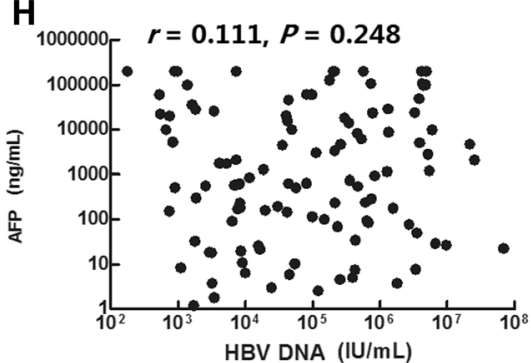

I

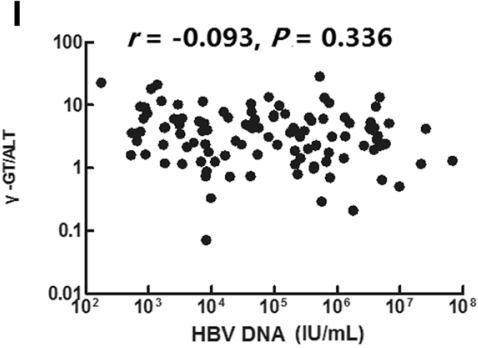

Figure 3. Correlation of serum levels of PIVKA-II and AFP and the serum $\gamma$-GT/ALT ratio with HBV DNA. (A-C) Serum levels of PIVKA-II and AFP and the serum $\gamma$-GT/ALT ratio were compared in patients with HCC who were HBV DNA+ and HBV DNA-. (D-F) Serum levels of PIVKA-II and AFP and the serum $\gamma$-GT/ ALT ratio were compared in patients with CHB who were HBV DNA+ and HBV DNA-. (G-I) Correlations of serum levels of PIVKA-II and AFP and the serum $\gamma$-GT/ALT ratio with serum levels of HBV DNA in patients with HCC who were HBV DNA+. 


\begin{tabular}{|l|l|l|l|}
\hline & HBV DNA+/HCC $(\mathbf{n}=\mathbf{1 1 0})$ & HBV DNA-/HCC $(\mathbf{n}=\mathbf{1 2 4})$ & $P$ value \\
\hline PIVKA-II $(\mathrm{mAU} / \mathrm{mL})$ & $7,363.10(922.13-30,000.00)$ & $1,883.99(132.38-18,618.54)$ & 0.003 \\
\hline AFP $(\mathrm{ng} / \mathrm{mL})$ & $796.75(76.28-20,710.95)$ & $247.20(14.80-5,783.58)$ & 0.031 \\
\hline$\gamma$-GT/ALT & $3.63(1.64-6.05)$ & $2.92(1.28-5.70)$ & 0.330 \\
\hline
\end{tabular}

Table 4. Serum levels of PIVKA-II and AFP and the serum $\gamma$-GT/ALT ratio in patients with HCC according to HBV DNA status. Data are expressed as medians (interquartile ranges). HCC hepatocellular carcinoma, PIVKA-II protein induced by vitamin $\mathrm{K}$ absence or antagonist II, AFP alpha-fetoprotein, $\gamma$-GT/ALT the ratio of $\gamma$-glutamyltransferase to alanine aminotransferase.

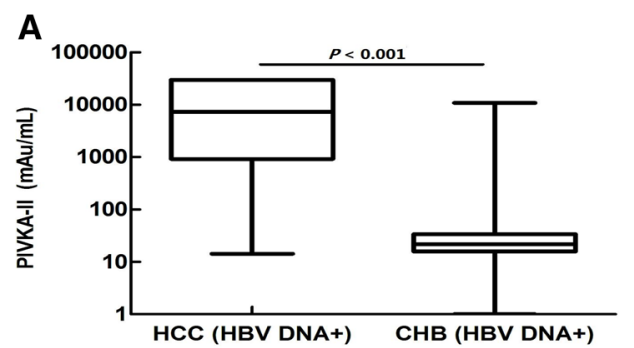

B
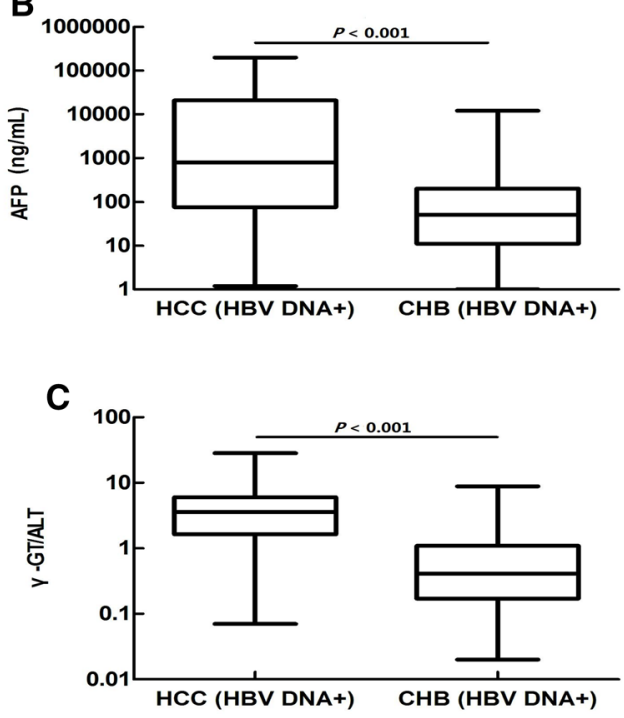
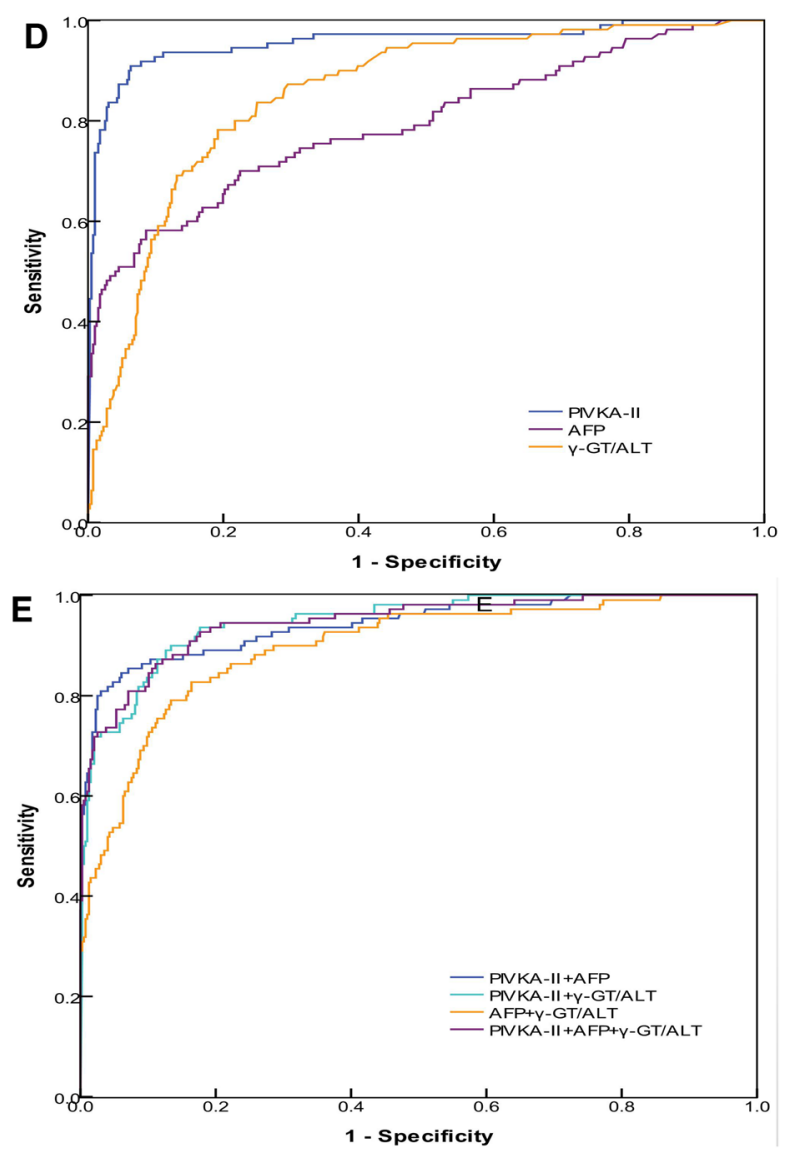

Figure 4. The diagnostic value of PIVKA-II, AFP, and the $\gamma$-GT/ALT ratio in patients with HCC and HBV DNA+ status. (A-C) PIVKA-II, AFP, and the $\gamma$-GT/ALT ratio were compared between patients with HCC and patients with CHB patients who were positive for HBV DNA. (D) ROC curves of PIVKA-II, AFP, and the $\gamma$-GT/ ALT ratio in patients with HCC and HBV DNA+. Patients with CHB served as controls. (E) ROC curve of the combinations of PIVKA-II, AFP, and the $\gamma$-GT/ALT ratio in patients with HCC who were positive for HBV DNA. Patients with CHB served as controls.

When the cut-off values of the $\gamma$-GT/ALT ratio and AFP and PIVKA-II levels were set as 1.580, $499.80 \mathrm{ng} /$ $\mathrm{mL}$, and $157.39 \mathrm{mAu} / \mathrm{mL}$, respectively, in patients with HCC who were positive for HBV DNA, there were no significant differences in AUROCs between the $\gamma$-GT/ALT ratio and AFP $(P=0.069)$. However, the AUROCs of both AFP and $\gamma$-GT/ALT were lower than that of PIVKA-II $(P<0.001, P<0.001$, respectively; Fig. 4D).

In the diagnosis of HBV DNA+/HCC, when PIVKA-II was combined with AFP, the AUROC of PIVKA-II decreased (0.942 versus 0.957, respectively); however, there were no significant differences in AUROCs between combined diagnosis and single diagnosis $(P=0.432)$. For the diagnosis of HCC patients who were positive for HBV DNA, the AUROC of AFP combined with the $\gamma$-GT/ALT ratio was 0.896, which was higher than that of AFP alone $(P=0.002)$. The highest AUROC for the combined diagnosis of HCC with HBV DNA+ was 0.946; however, there was no significant difference in AUROC between this and PIVKA-II ( $P=0.550$; Fig. 4E).

Diagnostic value of PIVKA-II, AFP, and the $\gamma$-GT/ALT ratio in patients with HBV DNA-I HCC. Serum levels of PIVKA-II and AFP and the serum $\gamma$-GT/ALT ratio in patients with HCC who were neg- 
A

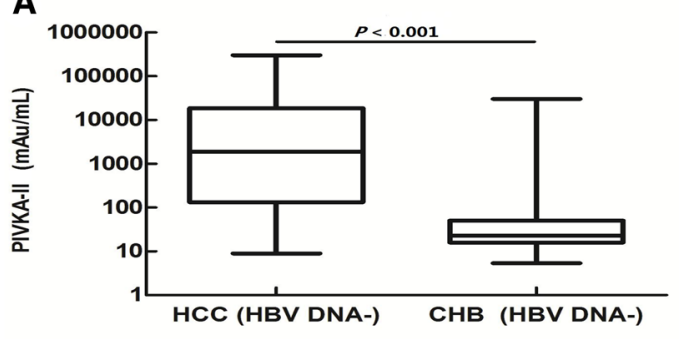

B
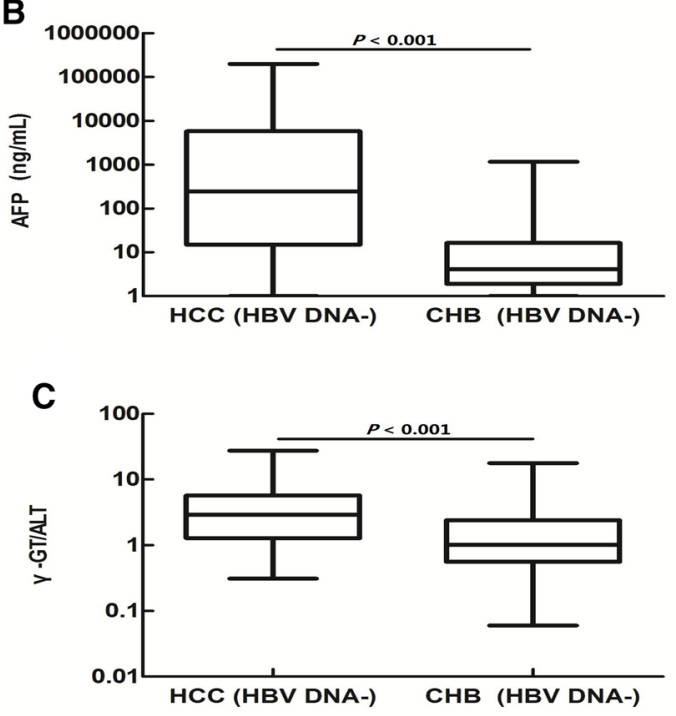
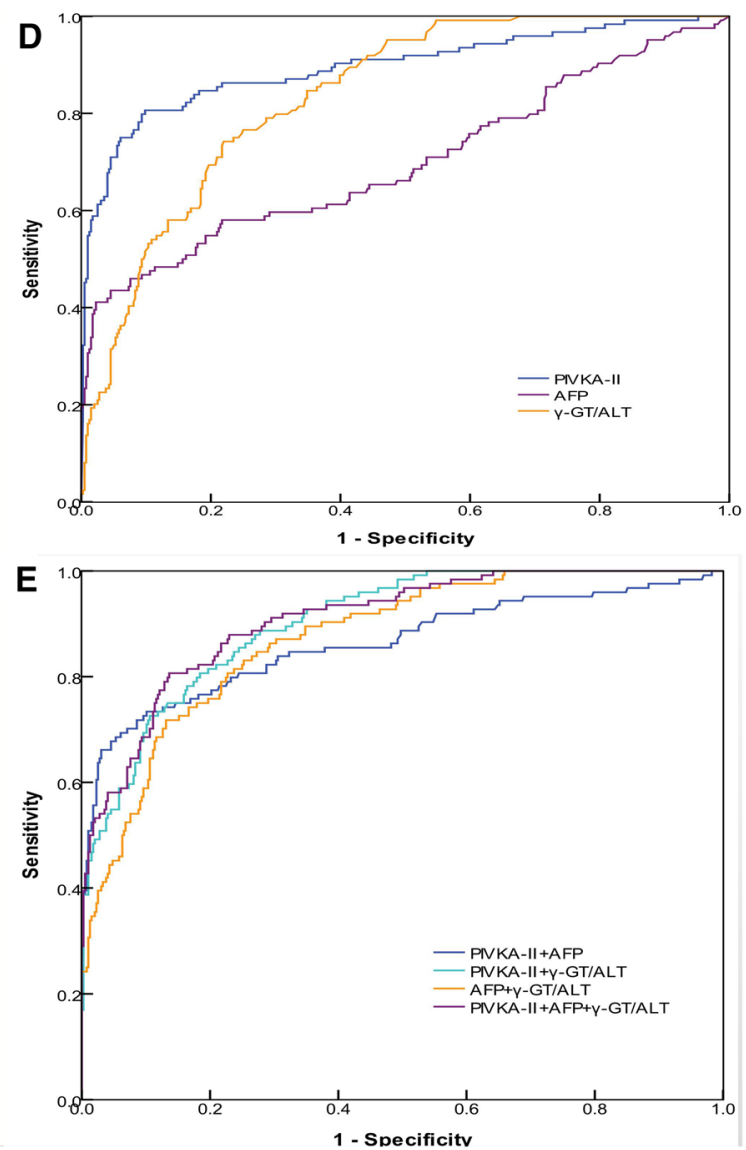

Figure 5. The diagnostic values of PIVKA-II, AFP, and the $\gamma$-GT/ALT ratio in patients with HCC who were negative for HBV DNA. (A-C) PIVKA-II, AFP, and the $\gamma$-GT/ALT ratio were compared between patients with HCC and patients with CHB who were negative for HBV DNA. (D) ROC curves of PIVKA-II, AFP, and the $\gamma$-GT/ALT ratio in patients with HCC who were negative for HBV DNA; patients with CHB served as controls. (E) ROC curve of the combinations of PIVKA-II, AFP, and the $\gamma$-GT/ALT ratio in patients with HCC who were negative for HBV DNA; patients with CHB served as controls.

ative for HBV DNA were higher than those in patients with $\mathrm{CHB}$ who were negative for HBV DNA $(P<0.001$, $P<0.001, P<0.001$; Fig. 5A-C).

When the cut-off values of the $\gamma$-GT/ALT ratio, AFP levels, and PIVKA-II levels were set as 1.400, $761.45 \mathrm{ng} /$ $\mathrm{mL}$, and $87.63 \mathrm{mAu} / \mathrm{mL}$, respectively, for patients with HCC who were negative for HBV DNA, the AUROCs of both the $\gamma$-GT/ALT ratio and PIVKA-II were higher than that of AFP $(P<0.001, P<0.001$, respectively). There was a significant difference between the AUROC of the $\gamma$-GT/ALT ratio and that of PIVKA-II $(P=0.027$; Fig. 5D). Compared with patients with HCC who were positive for HBV DNA, the diagnostic value of PIVKAII and AFP decreased in patients with HCC who were negative for HBV DNA $(P=0.007, P=0.020)$. However, there were no significant differences in the diagnostic value of the $\gamma$-GT/ALT ratio between patients with HCC who were positive for HBV DNA and patients with HCC who were negative for HBV DNA $(P=0.492$; Fig. 5D).

In patients with HCC who were negative for HBV DNA, when PIVKA-II combined with AFP was used to diagnose HBVDNA-/HCC, the AUROC of PIVKA-II decreased (0.863 and 0.895, respectively). However, when PIVKA-II combined with $\gamma$-GT/ALT ratio was used to diagnose HBVDNA-/HCC, the AUROC of PIVKA-II increased ( 0.902 and 0.895 , respectively). There were no significant differences in AUROCs between combined diagnosis and single diagnosis $(P=0.283, P=0.767$, respectively). And the AUROC of AFP combined with the $\gamma$-GT/ALT ratio in the diagnosis of patients with HCC without HBV DNA was 0.873, which was higher than that of AFP alone $(P<0.001)$. For the combined diagnosis of HCC with HBV DNA-, the highest AUROC was 0.907, However, there was no significant difference in AUROC between this and PIVKA-II $(P=0.620$; Fig. 5E). The diagnostic performance of PIVKA-II, AFP, and the ratio of $\gamma$-GT/ALT for HCC with and without HBV DNA positivity are shown in Table 5.

\section{Discussion}

AFP is the most commonly applied tumour marker in HCC; however, its sensitivity varies (33-85\%, mean: $56.3 \%$ ), which is not optimal for early diagnosis of $\mathrm{HCC}^{38}$. Therefore, there is an urgent need to identify better serological biomarkers, either alone or in combination with AFP, for the early diagnosis of HCC. In particular, markers with better ability to discriminate HCC from hepatitis viral infection are required. PIVKA-II is known to be abnormally expressed in liver tissues and elevated in the serum of patients with HCC. The sensitivity 


\begin{tabular}{|c|c|c|c|c|c|c|c|c|c|c|c|c|}
\hline & \multicolumn{6}{|c|}{ HCC (HBV DNA+) } & \multicolumn{6}{|c|}{ HCC (HBV DNA-) } \\
\hline & \begin{tabular}{|l|} 
Cut-off \\
\end{tabular} & AUROC $(95 \% \mathrm{CI})$ & SEN (\%) & SPE (\%) & PPV (\%) & NPV (\%) & Cut-off & AUROC (95\% CI) & SEN (\%) & SPE (\%) & PPV (\%) & NPV (\%) \\
\hline $\begin{array}{l}\text { PIVKA-II (mAu/ } \\
\mathrm{mL})\end{array}$ & 157.39 & \begin{tabular}{|l|}
$0.957(0.932-$ \\
$0.983)$
\end{tabular} & 90.90 & 93.70 & 80.00 & 97.38 & 87.63 & \begin{tabular}{|l|}
$0.895(0.857-$ \\
$0.933)$
\end{tabular} & 80.60 & 90.20 & 71.94 & 93.70 \\
\hline $\operatorname{AFP}(n g / m L)$ & 499.80 & \begin{tabular}{|l|}
$0.795(0.741-$ \\
$0.848)$
\end{tabular} & 58.20 & 91.40 & 65.31 & 88.73 & 761.45 & \begin{tabular}{|l|}
$0.699(0.638-$ \\
$0.759)$
\end{tabular} & 43.50 & 95.50 & 75.00 & 84.38 \\
\hline$\gamma$-GT/ALT & 1.58 & \begin{tabular}{|l|}
$0.855(0.817-$ \\
$0.893)$
\end{tabular} & 78.20 & 80.80 & 53.09 & 90.40 & 1.40 & \begin{tabular}{|l|}
$0.837(0.801-$ \\
$0.872)$
\end{tabular} & 74.20 & 78.00 & 51.40 & 90.62 \\
\hline PIVKA-II \& AFP & NA & \begin{tabular}{|l|}
$0.942(0.915-$ \\
$0.969)$
\end{tabular} & 84.50 & 93.90 & 79.49 & 95.63 & NA & \begin{tabular}{|l|}
$0.863(0.819-$ \\
$0.907)$
\end{tabular} & 73.40 & 89.90 & 69.47 & 91.52 \\
\hline $\begin{array}{l}\text { PIVKA-II \& } \gamma \text {-GT/ } \\
\text { ALT }\end{array}$ & NA & \begin{tabular}{|l|}
$0.948(0.926-$ \\
$0.970)$
\end{tabular} & 90.00 & 86.60 & 65.13 & 96.89 & NA & \begin{tabular}{|l|}
$0.902(0.874-$ \\
$0.931)$
\end{tabular} & 80.60 & 81.60 & 57.80 & 93.08 \\
\hline AFP \& $\gamma$-GT/ALT & NA & $\begin{array}{l}0.896(0.862- \\
0.931)\end{array}$ & 82.70 & 83.60 & 58.33 & 94.57 & NA & \begin{tabular}{|l|}
$0.873(0.839-$ \\
$0.906)$
\end{tabular} & 71.80 & 86.90 & 63.12 & 90.77 \\
\hline $\begin{array}{l}\text { PIVKA-II \& AFP \& } \\
\gamma \text {-GT/ALT }\end{array}$ & NA & \begin{tabular}{|l|}
$0.946(0.921-$ \\
$0.970)$
\end{tabular} & 86.40 & 88.90 & 68.35 & 95.91 & NA & $\begin{array}{l}0.907(0.878- \\
0.936)\end{array}$ & 80.60 & 86.40 & 64.94 & 93.44 \\
\hline
\end{tabular}

Table 5. Performance values of PIVKA-II, AFP, and the $\gamma$-GT/ALT ratio in patients with HCC with different HBV DNA statuses. HCC hepatocellular carcinoma, SEN sensitivity, SPE specificity, $P P V$ positive predictive value, $N P V$ negative predictive value, $P I V K A-I I$ protein induced by vitamin $\mathrm{K}$ absence or antagonist II, $A F P$ alpha-fetoprotein, $\gamma$-GT/ALT ratio of $\gamma$-glutamyl transferase to alanine transaminase, NA not applicable.

and specificity of PIVKA-II for the diagnosis of HCC may be superior to AFP, but the roles of PIVKA-II in HBV-related HCC might vary a lot considering different mechanisms of hepatocarcinogenesis among different aetiologies $^{39}$. PIVKA-II coupled with AFP has been routinely used for HCC screening. However, these indicators, along with false positive or false negative sometimes ${ }^{40}$. New markers and more cost-effective, appropriate combination of these markers for the diagnosis and surveillance for HBV-related HCC are urgently needed.

$\gamma$-GT is generally considered a biomarker of alcoholic hepatitis ${ }^{41,42}$. In HCC, particularly advanced HCC, cancer cells produce a certain amount of $\gamma$-GT, which is abnormally elevated in the serum of patients with $\mathrm{HCC}^{42}$, however, $\gamma$-GT is also increased in patients with CHB. Therefore, HCC and CHB cannot be distinguished by measuring serum $\gamma$-GT levels alone. ALT, which does not increase or even decreases in HCC, is more sensitive and is increased to varying degrees in almost all types of hepatitis. Therefore, it is necessary to evaluate whether the $\gamma$-GT/ALT ratio can be used as a diagnostic marker of HBV-related HCC.

In this study, we found that PIVKA-II and AFP levels and the $\gamma$-GT/ALT ratio were significantly higher in patients with HBV-related HCC than in patients with CHB. Moreover, the diagnostic values of PIVKA-II and the $\gamma$-GT/ALT ratio were significantly higher than that of AFP, and the $\gamma$-GT/ALT ratio and PIVKA-II had the same value in the diagnosis of early-stage HCC. Therefore, the ratio of $\gamma$-GT/ALT and the levels of PIVKA-II in the serum could be used for the diagnosis of early-stage HCC. Further analysis showed that the diagnostic sensitivity of PIVKA-II was significantly higher than that of the $\gamma$-GT/ALT ratio and AFP for HCC, HCC (HBV DNA+), and HCC (HBV DNA-), whereas the $\gamma$-GT/ALT ratio and the level of PIVKA-II in the serum had the same sensitivity for the diagnosis of early-stage HCC. Moreover, the diagnostic sensitivity of the $\gamma$-GT/ALT ratio was higher than that of AFP in early-stage HCC, HCC, HCC (HBV DNA+), and HCC (HBV DNA-). Therefore, the ratio of $\gamma$-GT/ALT was a useful biomarker for the diagnosis of HBV-related HCC. In addition, the cost for detection of $\gamma$-GT and ALT in the laboratory is very low, making these markers cost-effective indicators for the clinical diagnosis of HBV-related HCC.

Serum levels of PIVKA-II and AFP in patients with HCC who were positive for HBV DNA were significantly higher than those in patients with HCC who were negative for HBV DNA, indicating that continuous replication of HBV may promote the formation of PIVKA-II and AFP during the malignant transformation of hepatocytes. These changes may promote the occurrence of HCC in patients with $\mathrm{CHB}^{16}$. For patients with $\mathrm{HCC}$ without detectable HBV DNA, elevation of PIVKA-II and AFP was relatively lower than that in patients with HCC who were positive for HBV DNA. Thus, the diagnostic values of PIVKA-II and AFP were significantly lower in patients who were negative for HBV DNA than in patients who were positive for HBV DNA. In contrast, there were no significant differences in the diagnostic value of the $\gamma$-GT/ALT ratio among these patients, suggesting that the $\gamma$-GT/ALT ratio may be more useful in the diagnosis of patients with HCC who were negative for HBV DNA.

When the $\gamma$-GT/ALT ratio, AFP, and PIVKA-II were used in combination for the diagnosis of early-stage HCC, HCC, HCC with HBV DNA+, and HCC with HBV DNA-, the diagnostic performance of the $\gamma$-GT/ALT ratio combined with AFP or PIVKA-II was better than that of the biomarkers alone. The AUROCs of PIVKA-II combined with $\gamma$-GT/ALT ratio for the diagnosis of early-stage HCC, HCC, HCC with HBV DNA+, and HCC with HBV DNA- were higher than those of PIVKA-II combined with AFP and AFP combined with the $\gamma$-GT/ ALT ratio, implying improvement of the diagnostic value. Therefore, the combination of the $\gamma$-GT/ALT ratio and PIVKA-II may be useful for the differential diagnosis of HBV-related HCC and other benign liver diseases.

Our results also showed that the $\gamma$-GT/ALT ratio was positively correlated with tumour size, indicating that the $\gamma$-GT/ALT ratio may be another indicator for monitoring the progression of HBV-related HCC, similar to PIVKA-II and AFP. Therefore, further studies are necessary to explore the application of the $\gamma$-GT/ALT ratio in greater detail and assess the use of this marker in the monitoring of patients with HCC.

In conclusion, our study found the $\gamma$-GT/ALT ratio might be a potential biomarker for screening HBVrelated HCC patients and patients with $\mathrm{CHB}$ and in combination with the AFP and PIVKA-II could improve the 
diagnostic value. Thus, our findings may add an important non-invasive marker for diagnosis of HBV-related HCC. Our study results also showed a positive correlation of tumour size with $\gamma$-GT/ALT ratio, indicating that it may be a useful index in monitoring patients for progression of HBV-related HCC. However, this study did not make a more detailed staging of advanced HCC, which needs to be further demonstrated by follow-up experiments. In addition, the current study had some limitations, such as retrospective research, single-centre nature and small sample. These factors will lead to statistical errors regarding sensitivity, specificity and accuracy.

\section{Data availability}

The datasets generated during and analyzed during the current study are available from the corresponding author on reasonable request.

Received: 24 February 2020; Accepted: 22 July 2020

Published online: 11 August 2020

\section{References}

1. Bray, F. et al. Global cancer statistics 2018: GLOBOCAN estimates of incidence and mortality worldwide for 36 cancers in 185 countries. CA Cancer J. Clin. 68, 394-424. https://doi.org/10.3322/caac.21492(2018) (2018).

2. Forner, A., Reig, M. \& Bruix, J. Hepatocellular carcinoma. Lancet 391, 1301-1314. https://doi.org/10.1016/S0140-6736(18)30010 $-2(2018)(2018)$.

3. Ozakyol, A. Global epidemiology of hepatocellular carcinoma (HCC epidemiology). J. Gastrointestinal. Cancer. 48, 238-240. https ://doi.org/10.1007/s12029-017-9959-0(2017) (2017).

4. Chen, S. et al. The hepatitis B epidemic in China should receive more attention. Lancet 391, 1572. https://doi.org/10.1016/S0140 -6736(18)30499-9(2018) (2018).

5. Jemal, A. et al. Global cancer statistics. CA Cancer J. Clin. 61(69-90), 2011. https://doi.org/10.3322/caac.20107 (2011).

6. Wei, K. R. et al. Incidence and mortality of liver cancer in China, 2010. Chin. J. Cancer. 33, 388-394. https://doi.org/10.5732/ cjc.014.10088(2014) (2014).

7. Zheng, R., Zeng, H., Zhang, S. \& Chen, W. Estimates of cancer incidence and mortality in China, 2013. Chin. J. Cancer. 36, 66. https://doi.org/10.1186/s40880-017-0234-3(2017) (2017).

8. Ding, J. \& Wang, H. Y. Multiple interactive factors in hepatocarcinogenesis. Cancer Lett. 346, 17-23. https://doi.org/10.1016/j. canlet.2013.12.024(2014) (2014).

9. Chen, J. G. \& Zhang, S. W. Liver cancer epidemic in China: Past, present and future. Semin. Cancer Biol. 21, 59-69. https://doi. org/10.1016/j.semcancer.2010.11.002(2011) (2011).

10. Torre, L. A. et al. Global cancer statistics, 2012. CA Cancer J. Clin. 65, 87-108. https://doi.org/10.3322/caac.21262(2015) (2015).

11. Chen, W. et al. Cancer statistics in China, 2015. CA Cancer J. Clin. 66, 115-132. https://doi.org/10.3322/caac.21338(2016) (2016).

12. Kudo, M. Japan's successful model of nationwide hepatocellular carcinoma surveillance highlighting the urgent need for global surveillance. Liver Cancer. 1, 141-143. https://doi.org/10.1159/000342749(2012) (2012).

13. Park, S. J. et al. Usefulness of AFP, AFP-L3, and PIVKA-II, and their combinations in diagnosing hepatocellular carcinoma. Medicine. 96, e5811. https://doi.org/10.1097/MD.0000000000005811(2017) (2017).

14. Yu, R., Tan, Z., Xiang, X., Dan, Y. \& Deng, G. Effectiveness of PIVKA-II in the detection of hepatocellular carcinoma based on real-world clinical data. BMC Cancer. 17, 608. https://doi.org/10.1186/s12885-017-3609-6(2017) (2017).

15. Yang, T. et al. A novel online calculator based on serum biomarkers to detect hepatocellular carcinoma among patients with hepatitis B. Clin Chem. 65, 1543-1553. https://doi.org/10.1373/clinchem.2019.308965.(2019) (2019).

16. Wang, Q. et al. Diagnostic value of gamma-glutamyltransferase/aspartate aminotransferase ratio, protein induced by vitamin $\mathrm{K}$ absence or antagonist II, and alpha-fetoprotein in hepatitis B virus-related hepatocellular carcinoma. World J. Gastroenterol. 25, 5515-5529. https://doi.org/10.3748/wjg.v25.i36.5515(2019) (2019).

17. Li, X. H. \& Wei, L. The comparison among the guidelines for the diagnosis and treatment of hepatocellular carcinoma in China, AASLD and EASL. Zhonghua Gan Zang Bing Za Zhi. 27, 236-240. https://doi.org/10.3760/cma.j.issn.1007-3418.2019.03.015(2019) (2019).

18. Kudo, M. et al. Management of hepatocellular carcinoma in Japan: Consensus-based clinical practice guidelines proposed by the Japan Society of Hepatology (JSH) 2010 updated version. Dig. Dis. 29, 339-364. https://doi.org/10.1159/000327577(2011) (2011).

19. Izumi, N. Diagnostic and treatment algorithm of the Japanese Society of Hepatology: A consensus-based practice guideline. Oncology. 78, 78-86. https://doi.org/10.1159/000315234(2010) (2010).

20. Malek, N. P., Schmidt, S., Huber, P. \& Greten, T. F. The diagnosis and treatment of hepatocellular carcinoma. Dtsch Arztebl Int. 111, 101-106. https://doi.org/10.3238/arztebl.2014.0101(2014) (2014).

21. Huang, S. et al. Diagnostic performance of tumor markers AFP and PIVKA-II in Chinese hepatocellular carcinoma patients. Tumour Biol. https://doi.org/10.1177/1010428317705763(2017) (2017).

22. Zhang, Y. S., Chu, J. H., Cui, S. X., Song, Z. Y. \& Qu, X. J. Des- $\gamma$-carboxy prothrombin (DCP) as a potential autologous growth factor for the development of hepatocellular carcinoma. Cell Physiol. Biochem. 34, 903-915. https://doi.org/10.1159/000366308(2014) (2014).

23. Seo, S. I. et al. Diagnostic value of PIVKA-II and alpha-fetoprotein in hepatitis B virus-associated hepatocellular carcinoma. World J. Gastroenterol. 21, 3928-3935. https://doi.org/10.3748/wjg.v21.i13.3928(2015) (2015).

24. Ji, J. et al. Diagnostic evaluation of des-gamma-carboxy prothrombin versus alpha-fetoprotein for hepatitis b virus-related hepatocellular carcinoma in China: A large-scale, multicentre study. PLOS ONE 11, e0153227. https://doi.org/10.1371/journal.pone.01532 27(2016) (2016).

25. Lok, A. S. et al. Des-gamma-carboxy prothrombin and alpha-fetoprotein as biomarkers for the early detection of hepatocellular carcinoma. Gastroenterology 138, 493-502. https://doi.org/10.1053/j.gastro.2009.10.031(2010) (2010).

26. Pote, N. et al. Performance of PIVKA-II for early hepatocellular carcinoma diagnosis and prediction of microvascular invasion. J. Hepatol. 62(848-854), 2015. https://doi.org/10.1016/j.jhep.2014.11.005 (2015).

27. Wang, X. et al. Diagnostic value of prothrombin induced by the absence of vitamin K or antagonist-II (PIVKA-II) for early stage HBV related hepatocellular carcinoma. Infect. Agent Cancer. 12, 47. https://doi.org/10.1186/s13027-017-0153-6(2017) (2017)

28. Khan, S. A., Sirivelu, B., Saibaba, K., Sridevi, N. \& Iyyapu, K. Evaluation of diagnostic utility of protein induced by vitamin K absence-II (PIVKA-II) in hepatocellular carcinoma. Indian J. Med. Biochem. 23, 298-302. https://doi.org/10.5005/jp-journals10054-0107(2019) (2019).

29. Tsuchiya, N. et al. Biomarkers for the early diagnosis of hepatocellular carcinoma. World J. Gastroenterol. 21, 10573-10583. https ://doi.org/10.3748/wjg.v21.i37.10573(2015) (2015).

30. Whitfield, J. B. Gamma glutamyl transferase. Crit. Rev. Clin. Lab. Sci. 38, 263-355. https://doi.org/10.1080/20014091084227(2001) (2001). 
31. Silva, I. S. et al. Role of $\gamma$-glutamyl transferase activity in patients with chronic hepatitis $\mathrm{C}$ virus infection. Gastroenterol. Hepatol. 19, 314-318. https://doi.org/10.1111/j.1440-1746.2003.03256.x(2004) (2004).

32. Torruellas, C. et al. Diagnosis of alcoholic liver disease. World J. Gastroenterol. 20, 11684-11699. https://doi.org/10.3748/wjg.v20. i33.11684(2014) (2014).

33. Poynard, T. et al. Biochemical markers of liver fibrosis in patients infected by hepatitis $\mathrm{C}$ virus: Longitudinal validation in a randomized trial. J. Viral. Hepat. 9, 128-133. https://doi.org/10.1046/j.1365-2893.2002.00341.x(2002) (2002).

34. Seto, W. K. et al. A new model using routinely available clinical parameters to predict significant liver fibrosis in chronic hepatitis B. PLoS ONE 6, e23077. https://doi.org/10.1371/journal.pone.0023077(2011) (2011).

35. Faber, W. et al. Long-term results of liver resection for hepatocellular carcinoma in noncirrhotic liver. Surgery. 153, 510-517. https ://doi.org/10.1016/j.surg.2012.09.015(2013) (2013).

36. Wang, T. et al. Combination of dual serum fluorescence, AFP and hepatic function tests is valuable to identify HCC in AFP-elevated liver diseases. Oncotarget. 8, 97758-97768. https://doi.org/10.18632/oncotarget.22050(2017) (2017).

37. Chinese Society of Hepatology and Chinese Society of Infectious Diseases; Chinese Medical Association. The guideline of prevention and treatment for chronic hepatitis B: A 2015 update. Zhongguo Ganzangbing Zazhi. 7, 1-18. https://doi.org/10.3969/j. issn.1674-7380.2015.03.001(2015) (2015).

38. Roberts, L. R. et al. Imaging for the diagnosis of hepatocellular carcinoma: A systematic review and meta-analysis. Hepatology 67, 401-421. https://doi.org/10.1002/hep.29487(2018) (2018).

39. Yu, R. et al. Efficacy of PIVKA-II in prediction and early detection of hepatocellular carcinoma: A nested case-control study in Chinese patients. Sci. Rep. 6, 35050. https://doi.org/10.1038/srep35050(2016) (2016).

40. Zhu, L. et al. A simple noninvasive index can predict hepatocellular carcinoma in patients with chronic hepatitis B. Sci. Rep. 7, 8954. https://doi.org/10.1038/s41598-017-09358-z(2017) (2017).

41. Tolstrup, J., Grønbæk, M., Tybjærg, H. A. \& Nordestgaard, B. Alcohol intake, alcohol dehydrogenase genotypes, and liver damage and disease in the Danish general population. Am. J. Gastroenterol. 104, 2182-2188. https://doi.org/10.1038/ajg.2009.370(2009) (2009).

42. Zhao, H. et al. Clinical characteristics analysis of 1,180 patients with hepatocellular carcinoma secondary to hepatitis B, hepatitis C and alcoholic liver disease. J. Clin. Lab. Anal. 34, e23075. https://doi.org/10.1002/jcla.23075(2019) (2019).

\section{Acknowledgements}

The authors thank Yan Xing $\mathrm{PhD}$, for her valuable support and technical assistance.

\section{Author contributions}

All authors contributed to the conceptualisation and design of the study; G.W., X.L. and Q.D. contributed to the clinical data collection and analysis, and prepared and wrote the first draft of this manuscript; G.Z. contributed to the clinical data collection; D.W. contributed to the statistical analysis; Q.W. and X.G. designed this study and revised the manuscript.

\section{Competing interests}

The authors declare no competing interests.

\section{Additional information}

Correspondence and requests for materials should be addressed to Q.W. or X.G.

Reprints and permissions information is available at www.nature.com/reprints.

Publisher's note Springer Nature remains neutral with regard to jurisdictional claims in published maps and institutional affiliations.

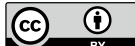

Open Access This article is licensed under a Creative Commons Attribution 4.0 International License, which permits use, sharing, adaptation, distribution and reproduction in any medium or format, as long as you give appropriate credit to the original author(s) and the source, provide a link to the Creative Commons license, and indicate if changes were made. The images or other third party material in this article are included in the article's Creative Commons license, unless indicated otherwise in a credit line to the material. If material is not included in the article's Creative Commons license and your intended use is not permitted by statutory regulation or exceeds the permitted use, you will need to obtain permission directly from the copyright holder. To view a copy of this license, visit http://creativecommons.org/licenses/by/4.0/.

(c) The Author(s) 2020 